\title{
The High Importance Role of Epidemiology in Health Management
}

Mobaraki K and Ahmadzadeh J*

Epidemiologist, Social Determinants of Health Research

Center, Urmia University of Medical Sciences, Urmia,

Iran

*Corresponding author: J amal Ahmadzadeh, Epidemiologist in Social Determinants of Health Research Center, Urmia University of Medical Sciences, Resalat Street, Urmia, Iran

Received: July 07, 2021; Accepted: August 31, 2021. Published: September 07, 2021

\section{Editorial}

Epidemiology is a scientific discipline; sometimes called "the basic science of public health". The identity of the person who coined the term epidemiology is unknown. The early applications of epidemiology were in the study of communicable disease epidemics, nutritional problems, and environmental hazards. The root of epidemiology comes from the Greek words meaning study upon populations: Epi, meaning "on or upon", demos, meaning "people", and logos, meaning "the study of" $[1,2]$. The word epidemic for the first time was used by Hippocrates. In fact, the pioneers of epidemiology and public health that have illuminated the deep historical roots of epidemiology were Hippocrates (a Greek physician, [370-460 BC]); Avicenna or Ibn Sina (a persian philosopher, physician, and scientist [980-1037]); Fracastoro (a renaissance physician and poet from Verona province of Italy [1478-1553]); John Graunt (he was known as the world's first epidemiologist and demographer from London [1620-1674]); Bernardino Ramazzini (a pioneer in epidemiology and especially in the field of occupational medicine [1633-1714]); William Farr ( he was the first compiler of abstracts at the general register office from England [1807-1883]); John Snow (he was considered the founding father of both epidemiology and anesthesiology [1813-1858]); Ignasz Semmelweis (he was a Hungarian physician [1818-1865]); Florence Nightingale (she was best known for her contribution to nursing, but she also was a statistician and epidemiologist [1820-1910]), and Janet Lane-Claypon (She was British pioneer in epidemiology also inventor of the modern case-control study [1877-1967]) [3].

Last's (2001) dictionary gives a detailed definition of epidemiology that includes these words 'The study of the distribution and determinants of health-related states or events in specified populations, and the application of this study to control of health problems' [4]. According to what it has done in the last 200 years, epidemiology is the science and practice. Some of them are looking at epidemiology from afar, may seem to believe that this field is nothing more than the use of statistical methods to study the problems and causes of diseases. But in fact, epidemiology is far beyond the science of applied statistics, and it is a science discipline rooted in biology, logic, and philosophy. For epidemiologists, statistical methods are merely used as an important tool, not the foundations of this science. Epidemiology is a very complex science. Epidemiology as a scientific discipline has a wide scope for working such as nutritional epidemiology, social epidemiology, environmental epidemiology, occupational epidemiology, clinical epidemiology, molecular epidemiology, etc. Therefore, with the above brief overview of the epidemiology, it is better that each epidemiologist has a specific area for working. One of the areas that are less addressed in the literature is the important role of epidemiology in health management. The authors believed that one of the areas that epidemiologists can work is management debate. Anyway, any manager must have a number of capabilities, for example, 1-understanding the concept of teamwork and ability to team building; 2-identify strategies and have planned on them; 3-policy making, coordination, implementation, supervision, assessment, and cost management. These are the key tasks of a manager does at work under normal circumstances. Certainly, during the work, there will be differences and frictions that a manager should minimize these differences or even remove them. A manager should have some meta capabilities to perform these mentioned tasks. A key element of these meta capabilities is the power of reasoning. After it, good observation, monitoring, analysis, have interacted well, being high-energy and also have the speed of action. A manager, along with having a coherent thought, he or she should also have knowledge in the specialized field. In a simple word, identify and understand basic concepts of health, different components of the health system, service providing models, health management and also having high power in the proper interpretation of health indicators, not just from the perspective of medical, surgical or any other specialty. Thus, any manager of the healthcare system partially should have some of these capabilities. Now we as an epidemiologist have to think about it, if supposedly these tasks to handling are in our shoulder, how much we are prepared. Does our specialized knowledge (epidemiology science) in this field can help us? Maybe at first glance, you have a question that in reality, dose someone is found to have all these capabilities? Now let us look again at the meta capabilities, which we have outlined for a manager. A good epidemiologist by default during the studding at university must learn that look at an event well and describe, analyze and interpret it well. In continue; clearly be able to report that event for the audience. Teamwork is very important in the work of epidemiologists. In fact, the nature of the epidemiologist's 
work in many sudden events is the speed of action. In the curriculum of epidemiologists, basic health knowledge is also usually taught. Epidemiologists need to know the basics of medicine and society and also they need to identify service providing models. Calculating the indicators and proper interpretation of health-related data, fit the audience is also an essential part of their work. An epidemiologist must be familiar with the economics of health.

Thus, if we look at the basis of meritocracy, we expect that an output part of epidemiology could to be relatively successful managers in the healthcare field. But, it is a misconception if we think that according to the above explanation all managers must be epidemiologists. The author in the present article feels that if someone has capable of managing and also has art, love, and interest in it, probably study in the field of epidemiology could help him or her to be more successful in the management. If you check look at the scientific resume of senior managers of World Health Organization or scientific resume of managers in other international organizations such as Food and Agriculture Organization, the United Nations high Commissioner for Refugees, etc. we will finally see that they have read the epidemiology lesson in the point of time.

In summary, we should try that a percentage of epidemiology students enter into the health care field. By that, we can use the knowledge and skills they have gained to promote community health. This important issue when will happen that the professors in the epidemiology field, could reinforce these management skills in those who are studying in this field. By that, we can create a system for students of epidemiology that convert their potential talents into action. With considering this issue that the epidemiologists work range varies from small groups to the large communities and also mention that the epidemiology science is at the forefront of saving human lives, it is clear that the reciprocal relationship between epidemiology knowledge and public health management and cooperation of epidemiologist as a managers in the public health system could markedly be used to predict epidemics and pandemic, identify possible causes of current and future disease outbreaks, implementation of planned, purposeful and participatory interventions to minimize the morbidity and mortality related to the disease and finally, it makes epidemiology more practical [5].

\section{Acknowledgments}

The authors dedicated this paper to all epidemiologists and successful managers in public health area across the world.

\section{References}

1. Bhopal RS. Concepts of epidemiology: Integrating the ideas, theories, principles, and methods of epidemiology: Oxford University Press. 2016.

2. Thorpe LE, Assari S, Deppen S, Glied S, Lurie N, Mauer MP, et al. The role of epidemiology in disaster response policy development. Annals of epidemiology. 2015; 25: 377-386.

3. Rothman KJ. Epidemiology: an introduction: Oxford University press. 2012.

4. John M. A dictionary of epidemiology: Oxford University Press. 2001.

5. Part of the speech from Professor Ali Akbar Haghdoost in $9^{\text {th }}$ Iranian Congress of Epidemiology. 2020. 